\title{
HUBUNGAN PELATIHAN APN DAN STATUS KEPEGAWAIAN DENGAN KETERAMPILAN PARTOGRAF UNTUK PEMANTAUAN PERSALINAN
}

\section{THE CORRELATION OF THE NORMAL DELIVERY CARE TRAINING AND THE EMPLOYEMENT STATUS WITH THE SKILL IN USING PARTOGRAPH FOR MONITORING THE DELIVERY}

\author{
Nevia Zulfatunnis ${ }^{1)}$, Hari Wujoso ${ }^{2)}$, Nunuk Suryani ${ }^{3)}$ \\ ${ }^{1), 3)}$ Stikes PKU Muhammadiyah Surakarta dan ${ }^{2)}$ Universitas Sebelas Maret \\ nevia.zulfa@gmail.com danwujoso@gmail.com
}

\begin{abstract}
Abstrak
Penyebab mortalitas dan morbilitas pada ibu bersalin adalah partus lama. Penggunaan partograf dapat diandalkan untuk mendeteksi secara dini adanya komplikasi persalinan. Status kepegawaian seseorang dapat dibedakan menjadi 2 yaitu PNS dan PTT. Diharapkan dengan status kepegawaian dapat mencegah partus lama melalui asuhan persalinan normal. Tujuan penelitian ini untuk mengetahui hubungan pelatihan APN dan status kepegawaian dengan ketrampilan pertograf untuk pemantauan persalinan. Jenis penelitian kuantitatif dengan desain observasional analitik dan pendekatan cross sectional. Populasi penelitian bidan Puskesmas Gatak I Sukoharjo yang berjumlah 41 orang, dan kesemuanya dijadikan sampel penelitian dengan teknik sampling jenuh. Alat pengumpul data menggunakan cheklist dan dokumentasi. Analisis data menggunakan regresi logistik. Hasil menunjukkan bahwa ada hubungan antara pelatihan APN dengan keterampilan partograf untuk pemantauan persalinan dan secara statistik signifikan dengan $(p=0,011)$. Tidak ada hubungan antara status kepegawaian dengan keterampilan partograf untuk pemantauan persalinan $(p=0,135)$. Nilai Negelkerke $R^{2}$ sebesar $32,2 \%$ berarti bahwa kedua variabel bebas (pelatihan APN dan status kepegawaian) mampu menjelaskan keterampilan partograf dalam pemantauan persalinan sebesar 32,2\% dan sisanya yaitu sebesar 67,8\% dijelaskan oleh faktor lain diluar model penelitian.
\end{abstract}

Kata kunci: pelatihan APN, status kepegawaian, keerampilan partograf, pemantauan persalinan

\begin{abstract}
The cause of mortality and morbility to maternal mothers is the longer labor. The use of partograph can be used to detect the complication in early stage. The employement status can be devided into two; they are the civil servant and irregular employee. It is expected that the employement status can prevent the longer labor through normal delivery care. The aim of this research is to find out the correlation of the normal delivery care training and the employement status with the skill in using partograph for monitoring the delivery. It was a quantitative research using analitic observational design with cross sectional approach. The population of the research were the midwives of Community Health Care of Gatak Sukoharjo that were 41 people; and all of them were included in the sample using boring sampling technique. The data collecting used checklist and documentation. The data analysis used the logistic regression. Result shows that there is correlation between the normal delivery care training and the skill in using partograph for monitoring the elivery with significance $(p=0,011)$. There is no correlation between the employment status and the skill in using partograph for monitoring the delivery $(p=0,135)$. Negelkerke value $R^{2}$ was $32,2 \%$ means that both of free variables (normal delivery care training and the employement status) can discribe the skill in using partograph in monitoring the delivery that was 32,2\% and the rest that was 67,8\% discribed by other factors outside the research.
\end{abstract}

Keywords: normal delivery care training, employement status, skill in using partograph, delivery monitoring 


\section{PENDAHULUAN}

Salah satu ciri negara yang sedang berkembang adalah masalah kesehatan yang masih rendah. Di negara Indonesia rendahnya kesehatan ditandai dengan masih tingginya angka kematian pada ibu. Hasil Survey Demografi dan Kesehatan Indonesia (SDKI) tahun 2012 angka kematian ibu secara nasional adalah 359 per 100.000 kelahiran hidup Rata-rata kematian ini jauh melonjak dibanding hasil SDKI 2007 yang mencapai 228 per 100 ribu.

Penyebab kematian ibu ada dua yaitu secara langsung dan tidak langsung. Penyebab langsung kematian ibu yaitu perdarahan, eklampsia dan infeksi. Sedangkan penyebab tidak langsung antara lain adalah ibu hamil menderita penyakit atau komplikasi lain yang sudah ada sebelum kehamilan, misalnya hipertensi, penyakit jantung, diabetes, hepatitis, anemia, malaria (Purbadewi dan Ulvie, 2013).

Dari berbagai faktor yang berperan pada kematian ibu dan bayi, kemampuan kinerja petugas kesehatan berdampak langsung pada peningkatan kualitas pelayanan kesehatan ibu. Cakupan pelayanan kehamilan, persalinan dan nifas oleh tenaga terlatih adalah kunci dari perbaikan status kesehatan ibu,bayi dan anak. Pengetahuan tentang kebidanan yang baik adalah identitas profesionalitas seorang bidan karena berfungsi sebagai kerangka kerja dalam pelaksanaan tugas (Sigridur et al., 2011).

Salah satu faktor yang sering menyebabkan mortalitas dan morbilitas pada ibu bersalin adalah partus lama. Partus lama terjadi apabila persalinan berlangsung lebih dari 24 jam pada primipara dan lebih dari 18 jam pada multipara. Partus lama akan menyebabkan infeksi, kehabisan tenaga, dehidrasi pada ibu, kadang dapat terjadi perdarahan post partum yang dapat menyebabkan kematian ibu. Pada janin akan terjadi infeksi, cedera dan asfiksia yang dapat meningkatkan kematian bayi. Untuk mencegah partus lama, melalui asuhan persalinan normal (Mobiliu, 2012).

Penggunaan partograf dapat diandalkan untuk memantau kondisi ibu dan janin serta kemajuan proses persalinan sehingga penolong persalinan (bidan, perawat, dokter umum atau spesialis obstetri) dapat membuat keputusan klinik sebagai upaya pengenalan adanya gangguan proses persalinan atau komplikasi dini agar dapat memberikan tindakan yang paling tepat dan memadai (Wiknjosastro, 2008).

Salah satu metode untuk dapat meningkatkan pengetahuan dan keterampilan bidan yaitu dengan Pelatihan Asuhan Persalinan Normal (APN). Pada prinsipnya APN adalah asuhan yang bersih dan aman dari setiap tahapan persalinan dan upaya pencegahan komplikasi terutama perdarahan pasca persalinan,hipotermia serta asfiksia bayi baru lahir. Secara umum tujuan APN adalah menjaga kelangsungan hidup dan memberikan derajat kesehatan yang tinggi bagi ibu dan bayinya melalui upaya yang terintegrasi dan lengkap tetapi dengan intervensi yang seminimal mungkin agar prinsip keamanan dan kualitas pelayanan dapat terjaga pada tingkat yang diinginkan atau optimal (Otto, Masni dan Naiem, 2012).

Dalam dunia kepegawaian atau ketenagakerjaan baik di lingkungan lemaga atau perusahaan pemerintah atau swasta tidak semua pegawai atau pekerja yang bekerja di dalamnya mempunyai status kepegawaian yang sama sehingga berbeda pula hak dan kewajiban masing-masing. Penggunaan istilah pegawan dan pekerja, kepegawaian dan ketenagakerjaan pada hakikatnya secara yuridis tidak mempunyai perbedaan arti dengan kaitannya dengan kehadirannya di dalam suatu perusahaan hanya berbeda lingkungan penggunaanya. UU 8/1974 tentang pokok-pokok kepegawaian dalam pasal 1 butir a mengemukakan bahwa yang dimaksud dengan pegawai (negeri) adalah orang-orang yang memenuhi syarat-syarat yang ditentukan dalam peraturan perundang-undangan yang berlaku, diangkat oleh pejabat yang berwenang dan diserahi tugas negara dalam suatu jabatan serta digaji menurut peraturan perundangundangan yang berlaku. Menurut UU 7/1981 butir d pekerja adalah tenaga kerja yang bekerja pada perusahaan dan menerima upah. Menurut UU 14/1969 tentang ketentuan-ketentuan pokok mengenai tenaga kerja pasal 1 , pengertian tenaga kerja ialah orang-orang yang mampu melakukan pekerjaan baik di dalam maupun di luar hubungan kerja guna menghasilkan jasa atau barang untuk memenuhi kebutuhan masyarakat.

Hasil studi pendahuluan di ini berkaitan erat dengan hasil pengamatan langsung oleh peneliti di Puskesmas Gatak I Sukoharjo bahwa sebagian besar bidan belum menerapkan penggunaan partograf dalam proses pemantauan kondisi ibu, kondisi janin dan kemajuan persalinan sehingga 
dalam menentukan suatu tindakan tidak didasarkan pada partograf tetapi dilaksanakan pada perkiraan saja, berdasarkan hal tersebut dapat diasumsikan bahwa penerapan penggunaan partograf di ruang kebidanan di Puskesmas Gatak I Sukoharjo belum dilaksanakan sesuai dengan apa yang diharapkan.

\section{METODE PENELITIAN}

Jenis penelitian kuantitatif dengan desain observasional analitik dan pendekatan cross sectional. Populasi penelitian bidan Puskesmas Gatak I Sukoharjo yang berjumlah 41 orang, dan kesemuanya dijadikan sampel penelitian dengan teknik sampling jenuh. Alat pengumpul data menggunakan cheklist dan dokumentasi. Analisis data menggunakan regresi logistic.

\section{HASIL DAN PEMBAHASAN}

Berdasarkan data penelitian tentang karakteristik sampel berdasarkan variabel penelitian dapat dijelaskan sebagai berikut:

Tabel 1. Pelatihan APN

\begin{tabular}{llc}
\hline \multirow{2}{*}{ Pelatihan APN } & \multicolumn{2}{c}{ Responden } \\
\cline { 2 - 3 } & $\mathrm{N}$ & $\%$ \\
\hline Belum Pernah & 10 & 24,4 \\
Pernah & 31 & 75,6 \\
\hline \multicolumn{1}{c}{ Jumlah } & 41 & 100 \\
\hline
\end{tabular}

Hasil penelitian menunjukkan bahwa responden yang belum pernah mengikuti pelatihan APN sebanyak 10 orang $(24,4 \%)$ dan responden yang pernah mengikuti pelatihan APN sebanyak 31 orang $(75,6 \%)$.

Hasil distribusi frekuensi tentang status kepegawaian dapat dilihat pada tabel sebagai berikut:

Tabel 2. Status Kepegawaian

\begin{tabular}{|c|c|c|}
\hline \multirow{2}{*}{ Status Kepegawaian } & \multicolumn{2}{|c|}{ Responden } \\
\hline & $\mathrm{N}$ & $\%$ \\
\hline PTT & 12 & 29,3 \\
\hline PNS & 29 & 70,7 \\
\hline Jumlah & 41 & 100 \\
\hline
\end{tabular}

Hasil penelitian menunjukkan bahwa responden yang berstatus sebagai Pegawai Tidak Tetap (PTT) sebanyak 12 orang $(29,3 \%)$ dan responden sebagai Pegawai Negeri Sipil (PNS) sebanyak 29 orang $(70,7 \%)$.

Hasil distribusi frekuensi tentang Keterampilan partograf untuk pemantauan persalinan pada tabel sebagai berikut:

Tabel 3. Keterampilan Partogram untuk Pemantauan Persalinan

\begin{tabular}{lcc}
\hline \multirow{2}{*}{$\begin{array}{c}\text { Keterampilan } \\
\text { Partograf }\end{array}$} & \multicolumn{2}{c}{ Responden } \\
\cline { 2 - 3 } & $\mathrm{N}$ & $\%$ \\
\hline Tidak terampil & 8 & 19,5 \\
Terampil & 33 & 80,5 \\
\hline \multicolumn{1}{c}{ Jumlah } & 41 & 100 \\
\hline
\end{tabular}

Hasil penelitian menunjukkan bahwa responden yang tidak terampil dalam penggunaan partograf dalam pemantauan persalinan sebanyak 8 orang $(19,5 \%)$ dan responden yang terampil untuk pemantauan persalinan sebanyak 33 orang $(80,5 \%)$.

Hasil perhitungan chi square hubungan pelatihan APN dengan keterampilan partograf menunjukkan nilai Odds Ratio sebesar 9,33 berarti pegawai yang pernah mengikuti pelatihan APN mempunyai kemungkinan 9,33 kali lebih terampil dalam penggunaan partograf untuk pemantauan persalinan dibandingkan pegawai yang belum pernah mengikuti pelatihan APN. Hasil uji Chi-Square diperoleh nilai fisher exact sebesar $0,013<0,05$ berarti menunjukkan ada hubungan yang signifikan antara pelatihan APN dengan keterampilan partograf untuk pemantauan persalinan.

Hasil perhitungan chi square hubungan status kepegawaian dengan keterampilan partograf untuk pemantauan persalinan menunjukkan nilai Odds Ratio sebesar 3,13 berarti pegawai yang berstatus Pegawai Negeri Sipil (PNS) mempunyai kemungkinan 3,13 kali lebih terampil dalam penggunaan partograf untuk pemantauan persalinan dibandingkan pegawai yang berstatus sebagai Pegawai Tidak Tetap (PTT). Hasil uji Chi-Square diperoleh nilai fisher exact sebesar 0,158 > 0,05 berarti menunjukkan tidak ada hubungan yang signifikan antara status kepegawaian dengan keterampilan partograf untuk pemantauan persalinan

Hasil perhitungan analisis multivariat menggunakan regresi logistik ganda untuk 
mengetahui hubungan pelatihan APN dan status kepegawaian dengan keterampilan partograf untuk pemantauan persalinan dapat dilihat pada tabel 4.

Tabel 4. UJi Regresi Logistik

\begin{tabular}{lcccc}
\hline \multirow{2}{*}{ Variabel } & \multirow{2}{*}{$\begin{array}{c}\text { Exp (B) } \\
\text { (OR) }\end{array}$} & $\begin{array}{c}\text { Batas } \\
\text { bawah }\end{array}$ & $\begin{array}{c}\text { Batas } \\
\text { atas }\end{array}$ & \multirow{2}{*}{ W Uji } \\
Weld \\
\hline $\begin{array}{l}\text { Pelatihan APN } \\
\text { Status }\end{array}$ & 11,34 & 1.74 & 73,87 & .011 \\
Kepegawaian & 4,25 & 0,64 & 28.30 & .135 \\
N observasi & 91 & & & \\
-2 log likelihood 31,22 & & & \\
Nagelkerke R ${ }^{2} 32,2 \%$ & & & \\
\hline
\end{tabular}

Hasil uji wald menunjukkan ada hubungan antara pelatihan APN dengan keterampilan partograf untuk kemampuan persalinan dan secara statistik signifikan $(\mathrm{OR}=11,34 ; \mathrm{CI}=95 \%$; 1,74 hingga 73,$87 ; \mathrm{p}=0,011$ ).

Hasil uji wald menunjukkan ada hubungan antara status kepegawaian dengan keterampilan partograf untuk kemampuan persalinan dan secara statistik signifikan $(\mathrm{OR}=4,25 ; \mathrm{CI}=95 \%$; 0,64 hingga 28,$30 ; \mathrm{p}=0,135$ ).

Nilai Negelkerke $\mathrm{R}^{2}$ sebesar $32,2 \%$ berarti bahwa kedua variabel bebas (pelatihan APN dan status kepegawaian) mampu menjelaskan keterampilan partograf dalam pemantauan persalinan sebesar $32,2 \%$ dan sisanya yaitu sebesar $67,8 \%$ dijelaskan oleh faktor lain diluar model penelitian.

\section{Hubungan Antara Pelatihan APN dengan Keterampilan Partograf Untuk Pemantauan Persalinan}

Hasil penelitian menunjukkan bahwa ada hubungan antara pelatihan APN dengan keterampilan partograf untuk pemantauan persalinan dan secara statistik signifikan dengan $(\mathrm{p}=0,011)$. Hasil penelitian ini mendukung penelitian terdahulu dari Otto, Masni dan Naiem (2012) bahwa pelatihan APN mempunyai hubungan yang bermakna dengan pengetahuan pertolongan persalinan. Amin, et al., (2013) dalam penelitiannya menunjukkan bahwa manfaat pelatihan, waktu pelatihan, kebijakan organisasi dan kebijakan pelatihan on the job and of the job berpengaruh pada kinerja. Berdasarkan hal tersebut maka pelatihan APN mampu mening- katkan keterampilan bidan dalam pemantauan persalinan.

Pelatihan adalah suatu perubahan pengertian dan pengetahuan atau keterampilan yang dapat diukur. Pelatihan dilakukan terutama untuk memperbaiki efektivitas pegawai dalam mencapai hasil kerja yang telah ditetapkan dengan maksud memperbaiki penguasaan keterampilan dan teknik-teknik pelaksanaan pekerjaan tertentu secara teliti dan rutin. Pelatihan APN merupakan salah satu aspek penting untuk menjamin keberhasilan pelaksanaan pemantauan persalinan. Hal ini sesuai dengan pernyataan dari Handoko (2007) bahwa pelatihan dilaksanakan untuk memberikan keterampilan, pengetahuan baru, dan penyegaran. Salah satu tujuan pelatihan APN adalah Memberikan pengetahuan \& ketrampilan pelayanan persalinan normal dan penanganan awal penyulit beserta rujukan yang berkualitas dan sesuai dengan prosedur standar. Manfaat Asuhan Persalinan Normal dalam mencegah komplikasi persalinan dan nifas yang mungkin dapat membantu dalam upaya memahami proses persalinan agar menghindari intervensi yang tidak tepat dan komplikasi yang tidak perlu terjadi, karena jelas bahwa kehadiran tenaga terlatih saat persalinan akan mengurangi kemungkinan komplikasi dan kejadian fatal.

\section{Hubungan Antara Status Kepegawaian dengan Keterampilan Partograf Untuk Pemantauan Persalinan}

Hasil penelitian menunjukkan bahwa tidak ada hubungan antara status kepegawaian dengan keterampilan partograf untuk pemantauan persalinan $(\mathrm{p}=0,135)$. Hasil penelitian ini mendukung penelitian Dwiyanti (2013) tidak ada hubungan antara status kepegawaian dengan penerapan partograf.

Status kepegawaian bidan merupakan keadaan/kedudukan bidan dalam hubungannya dengan lingkungan/ tempat kerja (Widyastuti, et al., 2008) Status khususnya status kepegawaian bidan merupakan salah satu pendorong seseorang melakukan perbuatan atau tindakan tertentu. Bila dilihat bahwa hubungan status kepegawaian tidak bermakna, hal inidikarenakan salah satu tantangan dalammemahami dan menerapkan teori Herzberg ialah memperhitungkan dengan tepat 
faktor mana yang lebih berpengaruh kuat dalam kehidupan seseorang, apakah yang bersifat intrinsik ataukah yang bersifat

Partograf memberi peringatan pada petugas kesehatan bahwa suatu persalinan berlangsung lama, kemungkinan adanya gawat ibu dan gawat janin, bahwa setiap wanita yang awalnya dalam keadaan normal/resiko tinggi sehingga memungkinkan untuk dirujuk (Nugraheny, 2009). Menurut Wiknjosastro (2008), partograf Adalah alat bantu untuk memantau kemajuan kala I persalinan dan informasi untuk membuat keputusan klinik. Tujuan utama dari penggunaan partograf untuk: mencatat hasil observasi dan kemajuan persalinan dengan menilai pembukaan serviks melalui periksa dalam, mendeteksi apakah proses persalinan berjalan secara normal. Dengan demikian juga dapat mendeteksi secara dini kemungkinan terjadinya partus lama, data pelengkap yang terkait dengan pemantauan kondisi ibu, kondisi bayi, grafik kemajuan proses persalinan, bahan dan medikamentosa yang diberikan, pemeriksaan laboratorium, membuat keputusan klinik dan asuhan atau tindakan yang diberikan dimana semua itu dicatatkan secara rinci pada status atau rekam medik ibu bersalin dan bayi baru lahir.

Mengingat pentingnya partograf tersebut demi pemantauan persalinan, maka hal ini menunjukkan bahwa status kepegawaian tidak begitu penting dalam hal keterampilan partograf bidan tersebut. Semua bidan baik PNS maupun PTT diharapkan mampu menggunakan partograf dalam pemantauan persalinan.

\section{Hubungan Pelatihan APN dan Status Kepegawaian dengan Ketrampilan Pertograf Untuk Pemantauan Persalinan}

Hasil penelitian diketahui bahwa nilai Negelkerke $\mathrm{R}^{2}$ sebesar $32,2 \%$ berarti bahwa kedua variabel bebas (pelatihan APN dan status kepegawaian) mampu menjelaskan keterampilan partograf dalam pemantauan persalinan sebesar $32,2 \%$ dan sisanya yaitu sebesar $67,8 \%$ dijelaskan oleh faktor lain diluar model penelitian. Hal ini menunjukkan bahwa selain faktor pelatihan APN masih terdapat beberapa faktor lain yang mempengaruhi keterampilan bidan dalam menggunakan partograf. Hal ini dibuktikan dari penelitian Otto, Masni dan Naiem (2012) bahwa beberapa faktor yang mempengaruhi penerapan partograf antara lain adalah pengetahuan bidan Dwiyanti (2013) dalam penelitiannya menunjukkan bahwa pengetahuan tentang partograf, motivasi bidan berhubungan dengan dengan penerapan partograf.

\section{SIMPULAN}

1. Ada hubungan antara pelatihan APN dengan keterampilan partograf untuk pemantauan persalinan dan secara statistik signifikan dengan $(\mathrm{p}=0,011)$.

2. Tidak ada hubungan antara status kepegawaian dengan keterampilan partograf untuk pemantauan persalinan $(p=0,135)$.

3. Nilai Negelkerke $\mathrm{R}^{2}$ sebesar $32,2 \%$ berarti bahwa kedua variabel bebas (pelatihan APN dan status kepegawaian) mampu menjelaskan keterampilan partograf dalam pemantauan persalinan sebesar $32,2 \%$ dan sisanya yaitu sebesar $67,8 \%$ dijelaskan oleh faktor lain diluar model penelitian.

\section{DAFTAR PUSTAKA}

Amin, A., Saeed, R., Lodhi, RN., Mizna, Simra, Iqbal, A., Tehreem, R. 2013. The Impact of Employees Training On the Job Performance in Education Sector of Pakistan. Middle-East Journal of Scientific Research. 17 (9): 1273-1278

Dwiyanti, D. 2013. Hubungan Pengetahuan, Motivasi Dan Status Kepegawaian Bidan Dengan Penerapan Partograf Di Kabupaten Sragen. Tesis. Surakarta: Program Pascasarjana Magister Kedokteran Keluarga Universitas Sebelas Maret.

Handoko, H. 2007. Manajemen Personalia \& Sumberdaya Manusia, Yogyakarta: BPFE UGM.

Mobiliu, S. 2012. Hubungan Pengetahuan Bidan dengan Penerapan Penggunaan Partograf di Ruang Kebidanan RSUD Toto Kabila Kabupaten Bone Balango. Jurnal Health \& Sport, Vol 2 No. 1: 121-13. 
PROFESI, Volume 14, Nomor 1, September 2016

Nugraheny, E. 2009. Asuhan Kebidanan Patologi. Yogyakarta: Pustaka Rihama.

Otto, S., Masni, Naiem, MF. 2012. Hubungan Pelatihan Asuhan Persalinan Normal Dengan Pengetahuan Dan Keterampilan Bidan Desa Dalam Pertolongan Persalinan Di Kota Gorontalo. Makasar: Universitas Hasanuddin.

Purbadewi, L dan Ulvie. Hubungan Tingkat Pengetahuan Tentang Anemia Dengan
Kejadian Anemia Pada Ibu Hamil. Semarang: Jurnal Gizi Universitas Semarang. Volume 2, Nomor 1: 31-39

Sigridur, H. Karlsdottir, S. 2011. The primacy of the good midwife in midwifery services: an evolving theory of professionalism in midwifery. Scandinavian Journal of Caring Sciences. Vol 2 No. 5:806-817.

Wijknjosastro, H. 2008. Ilmu Kebidanan. Jakarta: Bina Pustaka Sarwono Prawirohardjo. 